\title{
Secagem da polpa do umbu (Spondias tuberosa) em camada de espuma
}

\author{
Drying the pulp of umbu (Spondias tuberosa) in a foam layer \\ Secado de la pulpa de umbu (Spondias tuberosa) en una capa de espuma
}

Luana Maria Rufino de Souza

ORCID: https://orcid.org/0000-0001-5014-9223 Universidade Federal de Campina Grande, Brasil E-mail: luana.rufino@hotmail.com

Morgana Fabílola Cunha Silva Canuto ORCID: https://orcid.org/0000-0003-4880-3788 Universidade Federal de Campina Grande, Brasil E-mail: morganafabiola@hotmail.com Débora Rafaelly Soares Silva ORCID: https://orcid.org/0000-0002-7727-9535 Universidade Federal de Campina Grande, Brasil E-mail: deborarafaelly@yahoo.com.br

Fabiana Pimentel Macêdo Farias ORCID: https://orcid.org/0000-0003-4168-9601 Universidade Federal de Campina Grande, Brasil E-mail: fabiana.pimentel@professor.ufcg.edu.br Francislaine Suelia dos Santos ORCID: https://orcid.org/0000-0002-0814-4135 Universidade Federal de Campina Grande, Brasil E-mail: francislainesuelis@gamil.com

\begin{abstract}
Resumo
O umbu é um fruto nativo da região Nordeste de sabor levemente ácido e rico em vitamina C, entretanto, apresenta um alto teor de desperdícios por sua extrema perecibilidade. A Secagem é um método conhecido para diminuir a atividade de água dos alimentos e assim prolongar a vida útil dos frutos, permitindo um armazenamento prolongado e uma maior estabilidade e longevidade do produto, de modo a ter uma maior vida de prateleira. Dentre os meios de secagem, destacase a secagem em camada de espuma, que é um método de conservação com a finalidade de favorecer a conservação dos alimentos, preservando a qualidade do mesmo com um baixo custo de produção. Essa pesquisa teve por objetivo realizar a secagem em camada de espuma da polpa do umbu mediante a análise das curvas cinéticas de secagem, e através de um planejamento experimental, estudar os efeitos das variáveis de entrada: temperatura de secagem e tempo de batimento da espuma, sobre as variáveis respostas: ácido ascórbico e acidez total titulável. A análise estatística não gerou um modelo estatisticamente significativo ao nível de $95 \%$ de confiança para as variáveis respostas que foram estudadas diante da matriz experimental estudada.
\end{abstract}

Palavras-chave: Desidratação; Conservação; Desperdícios.

\begin{abstract}
The Umbu is a native fruit from the northeast region of acidic flavor and rich in vitamin C, however, has a high content of waste due to its extreme perishability. Drying is a known method for decreasing food water activity and extending fruit shelf life, allowing for extended storage and longer product stability and longevity for longer shelf life. Among the drying media, which can be dried on the foam layer, which is a conservation method that allows food conservation to be conserved, preserving quality even at low production costs. This research aimed to perform the drying in the Umbu pulp foam layer, using an analysis of the drying kinetic curves, and using an experimental design, studying the effects of the input variables: drying temperature and recovery time. foam, on the response variables: ascorbic acid and total titratable acidity. A statistical analysis did not generate a statistically significant model at the $95 \%$ confidence level for the response variables that were studied after the experimental matrix studied.
\end{abstract}

Keywords: Dehydration; Conservation; Waste.

\section{Resumen}

El Umbu es una fruta originaria de la región Nordeste con un sabor ligeramente ácido y rica en vitamina C, sin embargo, tiene un alto contenido de desperdicio debido a su extrema perecibilidad. El secado es un método conocido para disminuir la actividad hídrica de los alimentos y así prolongar la vida útil de la fruta, permitiendo un almacenamiento prolongado y una mayor estabilidad y longevidad del producto, con el fin de tener una vida útil más larga. Entre los medios de secado se destaca el secado por espuma, que es un método de conservación con el fin de favorecer la 
conservación de los alimentos, preservando su calidad con un bajo costo de producción. Esta investigación tuvo como objetivo realizar el secado en una capa de espuma de la pulpa de umbu mediante el análisis de las curvas cinéticas de secado, y mediante un diseño experimental, estudiar los efectos de las variables de entrada: temperatura de secado y tiempo de batido de la espuma, sobre la respuesta variables: ácido ascórbico y acidez total titulable. El análisis estadístico no generó un modelo estadísticamente significativo al 95\% de nivel de confianza para las variables de respuesta que se estudiaron contra la matriz experimental estudiada.

Palabras clave: Deshidratación; Conservación; Desperdicio.

\section{Introdução}

O Brasil se destaca por seu clima favorável e sua vasta extensão territorial, o que contribui de forma positiva para a atividade de fruticultura, sendo esta responsável por produzir cerca de 40,2 milhões de toneladas de frutas o que equivale a 4,8\% da produção mundial (DERAL/SEAB, 2017).

A fruticultura tem alavancado o PIB do país com a crescente produtividade, aumento dos empregos diretos e indiretos e ainda, proporcionando a produção de frutas em todos os meses chegando a todos os estados do Brasil e exportando para todo o mundo. Mas para isso, a indústria alimentícia busca constantemente a melhoria no manuseio, transporte e destino final desses alimentos que são altamente perecíveis e assim aumentar seu tempo de prateleira e diminuir a grande quantidade de perdas existentes. Já que, o país desperdiça mais de 30\% das frutas produzidas, de acordo com estimativas da Organização das Nações Unidas para a Alimentação e a Agricultura (FAO). Visto que, somente 24,1\% da população brasileira consome a quantidade de frutas e hortaliças recomendada pela Organização Mundial da Saúde (OMS) que é de 400 g diárias (Brasil, 2014).

Dentre os frutos cultivados em solos brasileiros, tem-se o umbu, fruto nativo da região nordeste com sabor levemente ácido que agrada o paladar, rico em vitamina $\mathrm{C}$, resistente a longos períodos de seca e que é fonte de renda para inúmeros agricultores da região. Porém, é um fruto de apenas uma safra ao ano e de extrema perecibilidade após sua colheita que apresenta apenas durabilidade de dois a três dias quando maduro.

Um grande problema enfrentado pelos fruticultores é a conservação dos frutos maduros, pois grande parte da colheita é desperdiçada. Este alto índice de desperdício é responsável por grandes aumentos de preço dos frutos para o consumidor final. Uma das principais causas de perdas é a deterioração, devido à alta quantidade de água livre presente nos frutos. Portanto, faz se necessário à utilização de métodos de conservação a fim de que o alimento se torne estável à deterioração química e microbiana, entre as várias formas de conservação estudadas está à desidratação ou secagem que vem se mostrando ser uma tecnologia viável para conservação dos frutos tropicais do Nordeste (Alves et al., 2011).

A desidratação, ou secagem, é uma técnica conhecida e eficiente para aumentar a durabilidade dos alimentos, diminuindo peso e volume, assim reduzindo os custos de manuseio e estocagem, por meio da extração da água presente nos alimentos através da exposição ao calor sob temperatura controlada, por evaporação, sendo um dos meios a secagem em estufa (Fellows, 2006). Garantido ao consumidor final o consumo de um alimento com propriedades nutricionais semelhantes ao in natura.

Este processo é amplamente utilizado pois melhora a estabilidade dos alimentos através da redução da atividade de água e consequentemente a minimização da atividade microbiológica e de algumas alterações físicas e químicas durante o armazenamento (Gurgel, 2014).

As informações presentes nas curvas de secagem são de grande importância para o desenvolvimento dos processos e para o dimensionamento de equipamentos, através delas, torna-se possível estimar o tempo da secagem de uma quantidade de produtos e, com o tempo necessário para a produção, tem-se a estimativa do gasto energético que refletirá no custo de processamento e, consequentemente, terá influência no preço final do produto.

A secagem por camada de espuma é um método relativamente antigo, mas que tem sido usada com frequência por se 
tratar de uma técnica que possibilita a transformação de insumos de difícil secagem em produtos de fácil reidratação, além de conservação de cor e sabor, retenção de compostos voláteis que quando aplicados outros métodos de desidratação são perdidos (Rajkumar \& Kailappan, 2006; Kudra \& Ratti, 2008). Tal método pode ser dividido em etapas fundamentais para sua realização: transformação do fruto em polpa, adição de aditivos na polpa e pôr fim a desidratação da matéria até que mude seu estado para pó. Esse processo pode ser executado em temperaturas relativamente baixas, em torno de $70{ }^{\circ} \mathrm{C}$ ou menos, e mantém alta qualidade e boa estabilidade dos produtos, com testes em café, sucos de laranja, uva, acerola, carambola, banana, abacaxi, coco, goiabas e outros produtos (Silva et al., 2005).

Ferreira (2017) realizou um estudo da secagem de jabuticaba (polpa e casca) pelo método de camada de espuma, concluindo que esse processo pode ser uma alternativa promissora na pós-colheita dessa importante fruta, além, de promover a retenção de componentes nutricionais, possibilita o aumento do consumo desse produto na forma de pó.

Dessa maneira, objetivou-se com a pesquisa estudar o processo de secagem da polpa do umbu (Spondias tuberosa) mediante método de secagem em camada de espuma, avaliando-se a qualidade do produto final.

\section{Materiais e Métodos}

O presente trabalho foi desenvolvido no Laboratório de Fenômenos de Transporte, Hidráulica, Irrigação e Drenagem em conjunto com os Laboratório de Química Experimental, no Centro de Desenvolvimento Sustentável do Semiárido (CDSA), da Universidade Federal de Campina Grande, Campus Sumé - PB e no Laboratório de Armazenamento e Processamento Agrícola, no Centro de Tecnologia e Recursos Naturais (CTRN), Campus de Campina Grande-PB. A pesquisa científica realizada foi de caráter quantitativo, conforme descrito por Pereira et. al (2018) caracteriza-se por gerar conjuntos ou massas de dados que podem ser analisados por meio de técnicas matemáticas.

\subsection{Obtenção da matéria-prima}

A polpa do umbu utilizada para o processo de secagem, foi proveniente de uma cooperativa de agricultores da cidade de Sumé-PB. A cooperativa foi responsável por toda parte de colheita até a transformação do fruto em polpa (Figura 1) e envase sem adição de açúcares, água, ou demais aditivos.

Figura 1. Polpa do umbu sem adição de emulsificante.

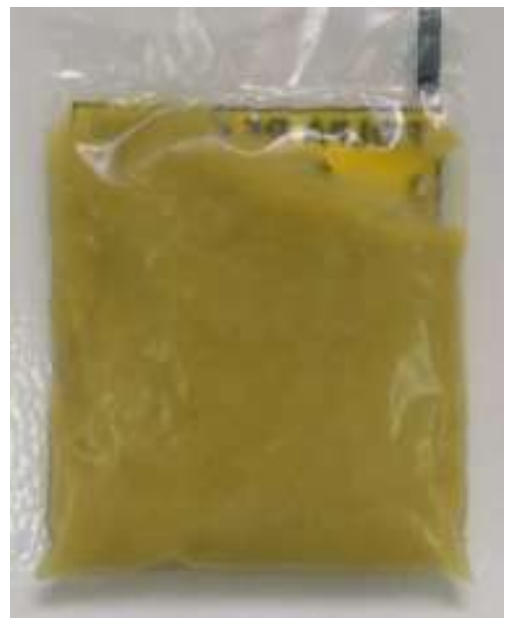

Fonte: Autoria própria. 


\subsection{Planejamento Experimental}

A técnica de planejamento experimental fatorial foi utilizada para avaliar a eficiência do processo de secagem em camada de espuma da polpa do umbu, podendo- se verificar as variáveis que apresentaram efeitos significativos sobre as variáveis respostas. A matriz planejamento teve como variáveis de entrada: temperatura de secagem e tempo de batimento da camada de espuma, enquanto que as variáveis respostas, em estudo, são: ácido ascórbico e acidez total titulável. Os níveis para cada variável estão apresentados na Tabela 1.

Tabela 1. Níveis das variáveis do planejamento fatorial.

\begin{tabular}{cccc}
\hline Variáveis independentes & Nível & Ponto central & Nível \\
& $(\mathbf{- 1})$ & $(\mathbf{0})$ & $(+\mathbf{1})$ \\
\hline $\mathrm{T}\left({ }^{\circ} \mathrm{C}\right)$ & 60 & 70 & 80 \\
$\mathrm{t}(\min )$ & 15 & 20 & 25 \\
\hline
\end{tabular}

Fonte: Autoria própria.

O planejamento fatorial realizado neste trabalho foi do tipo $22 \mathrm{com}$ a realização de mais três experimentos no ponto central, cuja matriz encontra-se descrita na Tabela 2.

Tabela 2. Matriz do planejamento experimental.

\begin{tabular}{ccc}
\hline Ensaios & $\begin{array}{c}\text { Temperatura } \\
\left({ }^{\circ} \mathbf{C}\right)\end{array}$ & $\begin{array}{c}\text { Tempo } \\
(\mathbf{m i n})\end{array}$ \\
\hline 1 & 60 & 15 \\
2 & 80 & 15 \\
3 & 60 & 25 \\
4 & 80 & 25 \\
5 & 70 & 20 \\
6 & 70 & 20 \\
7 & 70 & 20 \\
\hline
\end{tabular}

Fonte: Autoria própria.

A partir das variáveis respostas obtidas nos experimentos, os dados foram ajustados mediante regressão não linear com o uso do programa Statistica versão 6.0. Dessa maneira, os dados foram analisados com a finalidade de examinar a influência das variáveis de entrada, possibilitando a otimização do processo de secagem em estudo.

\subsection{Preparação da espuma}

Para obtenção da espuma foi feita uma mistura da polpa do umbu com o emulsificante (aditivo) onde foi submetida à agitação constante em uma batedeira doméstica. $O$ tempo de batimento utilizado para preparação da espuma encontra-se descrito na Tabela 1. Foram utilizadas $150 \mathrm{~g}$ da polpa e $5 \%$ do peso da amostra de emulsificante para a produção da camada de espuma. 


\subsection{Secagem}

A espuma produzida foi espalhada sobre bandejas de aço inoxidável em camada fina (Figura 2) e levadas para secagem em estufa com circulação de ar, em diferentes temperaturas e tempo de batimento, conforme descrito na Tabela 2. Os ensaios experimentais foram realizados em triplicata, sendo as pesagens realizadas em balança semianalítica, em intervalos de tempos estimados para os ensaios. As curvas cinéticas RX versus tempo foram plotados utilizando o Origin versão 6.0.

Figura 2. Espuma pronta para ser submetida ao processo de secagem.

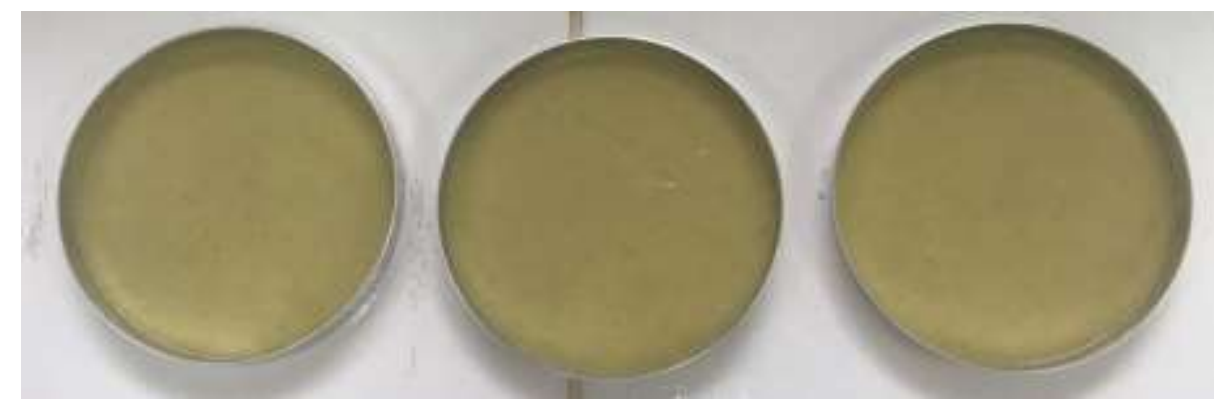

Fonte: Autoria própria.

A determinação da razão do teor de água foi calculada pela Equação 1:

$$
R X=\frac{X_{b s}-X_{e}}{X_{b s(\text { inicial })}-X_{e}}
$$

Em que, RX: razão de teor de água (adimensional); Xbs: teor de água em base seca; Xe: teor de água de equilíbrio; Xbs(inicial): teor de água inicial em base seca.

\subsection{Armazenamento}

O pó da polpa do umbu (Figura 3) foi armazenado em embalagens de polipropileno e guardados no dessecador do Laboratório de Química e solos para realização das análises físico-químicas.

Figura 3. Pó obtido armazenado em saco de polietileno.

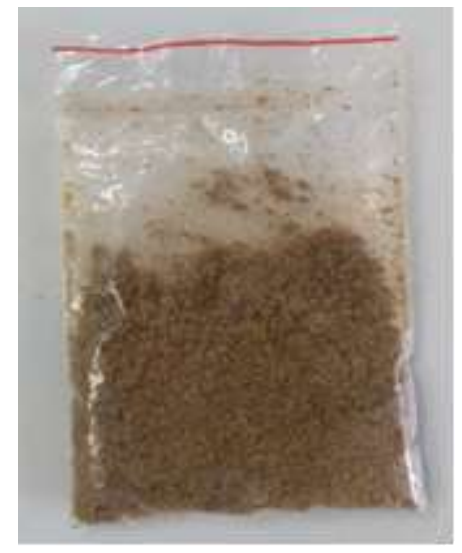

Fonte: Autoria própria. 


\subsection{Análises Físico-químicas da polpa do umbu in natura e do pó produzido}

A polpa do umbu in natura e o pó produzido após processo de secagem, passaram por análises de: acidez total titulável, ácido ascórbico, umidade e $\mathrm{pH}$. As análises físico-químicas foram efetuadas conforme métodos descritos pelas normas do Instituto Adolfo Lutz (2008), exceto a umidade que foi determinada mediante utilização do Analisador de umidade.

\subsubsection{Acidez total titulável (ATT)}

A acidez total titulável foi determinada por titulação volumétrica com solução de $\mathrm{NaOH} 0,1 \mathrm{~N}$. Foi usado aproximadamente $1 \mathrm{~g}$ da amostra diluída em $50 \mathrm{~mL}$ de água destilada, e posteriormente adicionada duas gotas de fenolftaleína (1\%). A solução de $\mathrm{NaOH} 0,1 \mathrm{~N}$ foi adicionada lentamente até a mudança de cor. Os resultados foram expressos em percentagem de ácido cítrico $(\mathrm{g} / 100 \mathrm{~g})$.

\subsection{2 Ácido ascórbico}

A determinação do ácido ascórbico foi feita através do método de Tillmans, na qual foi feita a diluição de $1,0 \mathrm{~g}$ da amostra com a adição de $50 \mathrm{~mL}$ de ácido oxálico, sendo a titulação realizada com a solução de Tillmans $0,02 \%$, até o ponto de viragem.

\subsubsection{Umidade}

Utilizou-se aproximadamente 1 grama de amostra na balança Analisador de umidade marca Shimadzu modelo MOC63 sob temperatura de $105^{\circ} \mathrm{C}$, seguido da leitura.

\subsection{4 pH}

$\mathrm{O} \mathrm{pH}$ da polpa foi determinado através de leitura direta em potenciômetro calibrado com soluções tampão de $\mathrm{pH} 4,0 \mathrm{e}$ 7,0. Para o pó, usou-se $3 \mathrm{~g}$ das amostras diluídas em $10 \mathrm{~mL}$ de água destilada, seguido da leitura e para a polpa in natura, foi utilizado $6 \mathrm{~g}$ diluídos em $20 \mathrm{~mL}$ de água destilada.

\section{Resultados e Discussão}

\subsection{Secagem}

Através dos dados obtidos na operação de secagem da polpa do umbu em camada de espuma, pôde-se obter as curvas de secagem com a finalidade do acompanhamento da taxa de secagem de acordo com as condições na qual o material foi submetido. Nas Figuras 4 e 5, encontram-se representadas as curvas cinéticas da secagem do umbu, referentes aos ensaios realizados, conforme condições descritas na Tabela 2. Essas curvas são apresentadas na forma adimensional do teor de água (RX), em função do tempo. 
Figura 4. Curva da razão do teor de água em função do tempo para a secagem da polpa do umbu em camada de espuma.

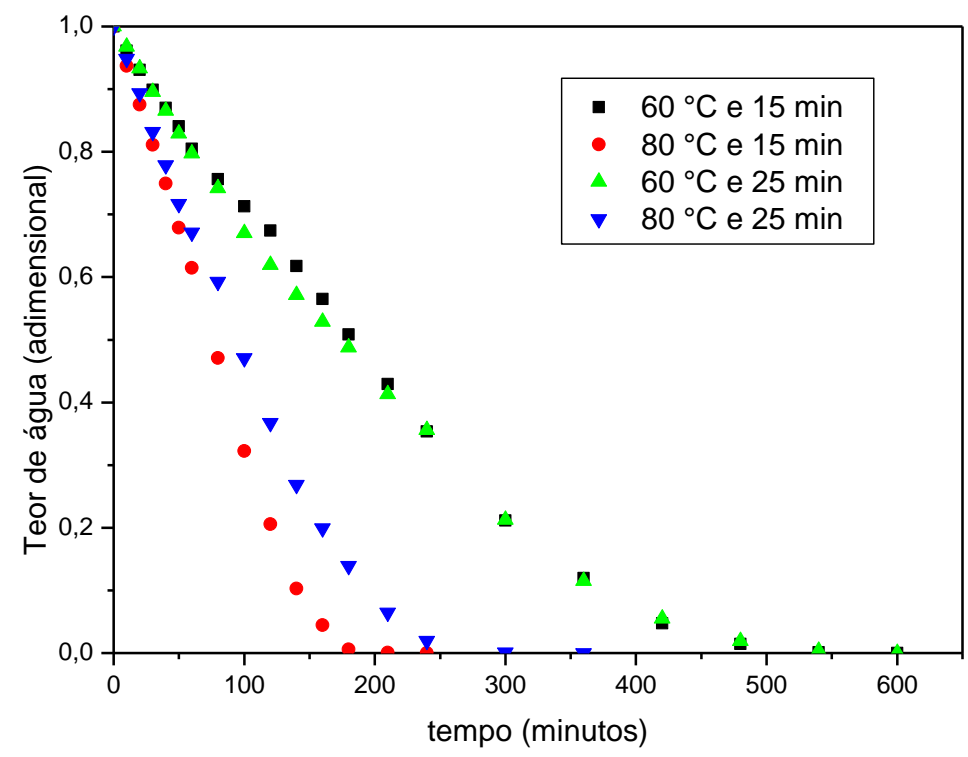

Fonte: Autoria própria.

Figura 5. Curva da razão do teor de água em função do tempo para a secagem da polpa do umbu em camada de espuma (Ponto central).

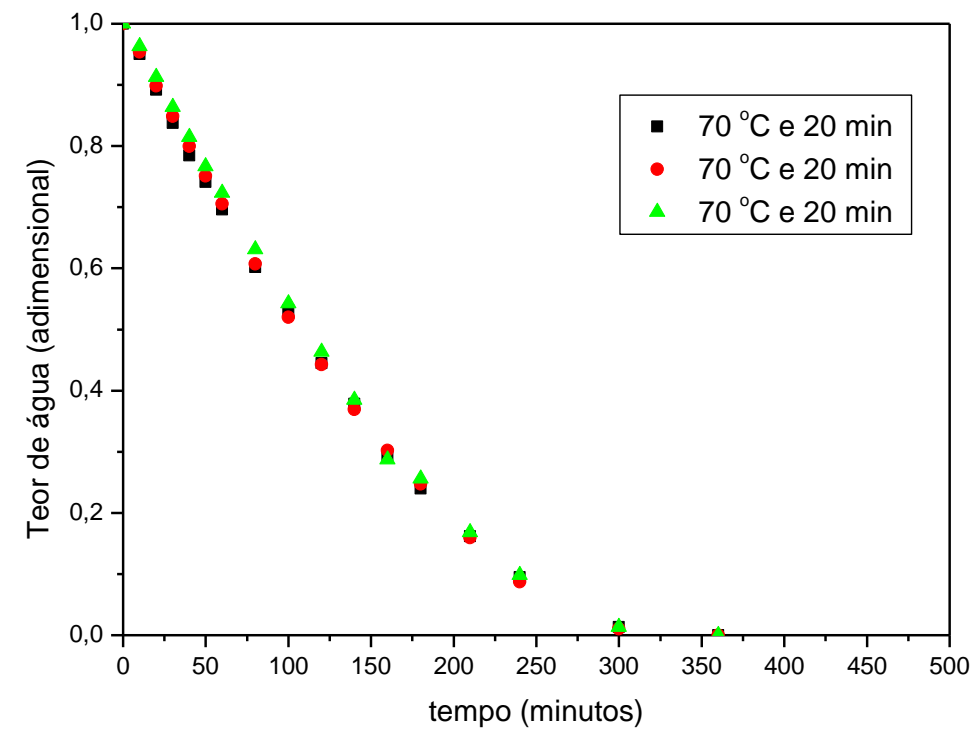

Fonte: Autoria própria.

Nota-se que a taxa de velocidade de secagem está diretamente relacionada com o aumento da temperatura, visto que, quanto mais alta a temperatura empregada na operação menor foi o tempo necessário para a estabilização da espuma. Esse procedimento também foi notado por Ferreira (2017) que estudou a secagem em camada de espuma da jabuticaba com temperaturas de $50^{\circ} \mathrm{C}, 60^{\circ} \mathrm{C}$ e $70^{\circ} \mathrm{C}$, onde constatou que a umidade foi reduzida com o passar do tempo, mas houve uma redução mais rápida para a temperatura de $70{ }^{\circ} \mathrm{C}$. Resultado semelhante foi reportado por Araújo et al. (2021), ao estudarem a cinética de secagem das polpas combinadas de noni e umbu nas temperaturas de 40,50,60 e $70{ }^{\circ} \mathrm{C}$, observaram que o aumento da 
temperatura do ar de secagem promoveu a elevação das taxas de remoção de água do produto.

O processo de secagem da espuma da polpa do umbu variou conforme a temperatura utilizada. O maior tempo de processamento foi de 600 minutos (10 horas) para a temperatura de $60{ }^{\circ} \mathrm{C}, 360$ minutos (6 horas) para a temperatura de $70{ }^{\circ} \mathrm{C}$ e 240 minutos (4 horas) para a temperatura de $80^{\circ} \mathrm{C}$. Esses tempos foram superiores aos obtidos por Gomes et al. (2017) que estudou a secagem em camada de espuma da acerola com 5\% de aditivos e obteve os tempos de 5, 3 e 3 horas para as respectivas temperaturas de 60,70 e $80^{\circ} \mathrm{C}$, onde foi verificado que com o aumento da temperatura, há uma diminuição no tempo do processamento. Pê et al. (2016) ao realizarem a secagem de polpa de caqui em camada de espuma na temperatura de $70{ }^{\circ} \mathrm{C}$, obtiveram tempo inferior ao reportado nesse estudo, no qual foi necessário120 min para que as formulações avaliadas atingissem o teor de água de equilíbrio.

De acordo com Moreira et al. (2018) as curvas de cinética de secagem de um produto dependem de vários fatores como velocidade do ar de secagem, teor de água inicial, teor de água final, umidade relativa do ar, temperatura, composição, pressão, entre outros. Mediante as curvas cinéticas, pôde-se observar que as espumas do umbu seca a $60{ }^{\circ} \mathrm{C}$ apresentaram menor remoção de água, quando comparadas com as espumas seca a $80^{\circ} \mathrm{C}$, sendo observado que a maior perda de água se deu para as espumas desidratadas a $80^{\circ} \mathrm{C}$, fato esse verificado por Pinheiro (2018) que realizou a cinética de secagem dos frutos do cajá com a finalidade de obtenção de farinha do epicarpo nas temperaturas de 40, 50, 60 e $70{ }^{\circ} \mathrm{C}$ onde obteve os tempos de 11,5; 9,0; 7,0 e $4,5 \mathrm{~h}$, respectivamente, e verificou que com aumento da temperatura, mais rápido a água do interior do material utilizado irá migrar para o exterior.

Pode-se visualizar que os ensaios realizados para o ponto central (Figura 5), tiveram um comportamento semelhante, podendo através desses dados, comprovar que os experimentos foram realizados com uma boa reprodutibilidade. Percebe-se também em ambas figuras que o tempo de batimento não influenciou de maneira expressiva quanto a cinética de secagem em todos os ensaios.

\subsection{Secagem}

A Tabela 3, apresenta os resultados obtidos para a caracterização físico-química da polpa do umbu in natura e do pó obtido mediante a secagem em camada de espuma. Ao verificar os valores encontrados para a polpa in natura, para os parâmetros analisados, pode-se comprovar que a mesma se encontra de acordo com o especificado pela Instrução normativa ${ }^{\circ} 37$ (Brasil, 2018), para que seja considerada como uma polpa de qualidade.

Tabela 3. Caracterização físico-química do umbu in natura e em pó.

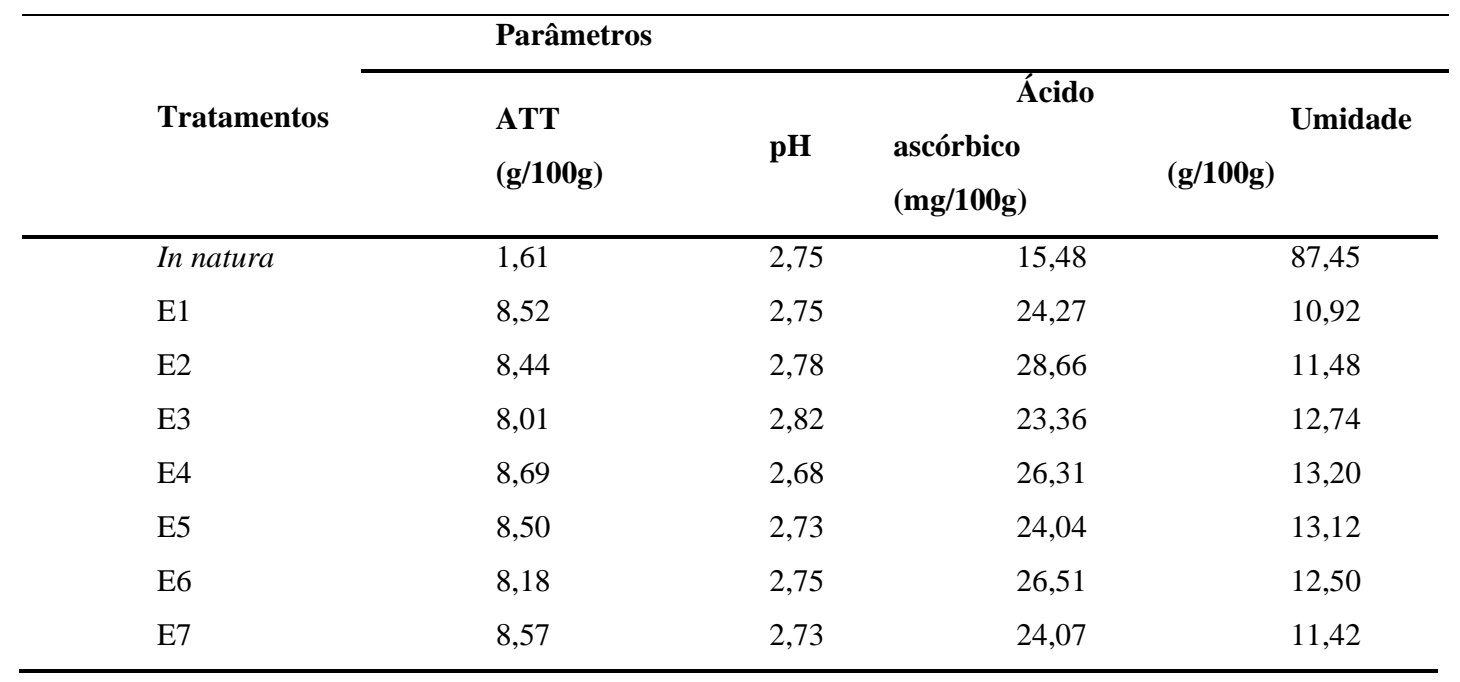


Com relação ao teor de acidez verifica-se que houve um aumento nos teores após a secagem. O mesmo fato ocorreu com Ferreira (2017) que analisou a secagem da jabuticaba (polpa e casca) e constatou um aumento na acidez em comparação com polpa do fruto, fato este que pode ser explicado em razão da perda de água, mediante processo de secagem, o que provoca um aumento na concentração de nutrientes na massa restante, a exemplo do teor de ácido cítrico presente no umbu.

Quanto ao pH não houve variação significativa tanto para a polpa de umbu como para o pó obtido após secagem, assegurando dessa forma o sabor ácido próprio do fruto. No estudo da caracterização do limão galego realizado por Neto et al. (2018), o pH obtido foi 2,69, estando muito próximo aos valores obtidos neste trabalho.

Em relação ao teor de ácido ascórbico verificou-se que houve um aumento da concentração deste componente, após o processo de secagem, quando comparado com o fruto in natura, fato este que pode está associado a redução do teor de água, acarretando concentração dos compostos da polpa. Esse fato também ocorreu em estudos realizados por Coelho et al. (2019) que realizaram secagem solar da manga espaga.

Observou-se que a umidade da polpa do fruto do umbu encontra-se com um valor bem aproximado ao da Tabela Brasileira de Composição de Alimentos NEPA (2011) que é de 90,2\% e ao de Silva et al. (2015) que obteve um valor de 89,045\% de umidade em seus estudos de caracterização físico-química do umbu em camada de espuma. Ainda é possível destacar a importância do estudo de umidade por se tratar de um parâmetro que está atrelado ao tempo de vida dos alimentos e sua durabilidade. Logo, constata-se que após o processo de secagem, a perda de água foi satisfatória, conforme dados observados na Tabela 3, atendendo assim a resolução da Comissão Nacional de Normas e Padrões para Alimentos (Brasil, 1978) que permite a quantidade máxima de $25 \%$ para frutas secas ou dessecadas. Dessa forma o baixo teor de umidade encontrado permite uma maior conservação do produto, uma vez que reduz a água disponível para o desenvolvimento dos microrganismos

\subsection{Análise da variância}

$\mathrm{Na}$ Tabela 4, tem-se a análise da variância (ANOVA) realizada com a finalidade de avaliar a influência que as condições empregadas, temperatura e tempo de batimento, durante a operação de secagem exerceram sobre as variáveis respostas, que são acidez total titulável e ácido ascórbico, para a secagem da polpa do umbu em camada de espuma.

Tabela 4. Análise da Variância (ANOVA).

\begin{tabular}{lcccc}
\hline Variável resposta & $\begin{array}{c}\text { Coeficiente de } \\
\text { correlação }\end{array}$ & $\begin{array}{c}\text { Teste } \mathbf{F} \text { calculado } \\
\left(\mathbf{F}_{\mathbf{c}}\right)\end{array}$ & $\begin{array}{c}\text { Teste } \mathbf{F} \text { tabelado } \\
\left(\mathbf{F}_{\mathbf{t}}\right)\end{array}$ & Teste $\mathbf{F}_{\mathbf{c}} / \mathbf{F}_{\mathbf{t}}$ \\
\hline Acidez Total Titulável & 0,88 & 3,43 & 9,28 & 0,37 \\
Ácido ascórbico & 0,87 & 3,29 & 9,28 & 0,35 \\
\hline
\end{tabular}

Fonte: Autoria própria.

De acordo com a tabela 4, constatou-se que para as variáveis respostas estudadas, não foi possível obter um modelo estatisticamente significativo, ao nível de $95 \%$ de confiança diante da matriz experimental estudada. Dessa forma, não foi possível obter um modelo codificado em função das variáveis independentes sobre as variáveis respostas.

O efeito das variáveis independentes (temperatura de secagem e tempo de batimento) sobre as variáveis dependentes, acidez total titulável e ácido ascórbico foram avaliadas na forma de diagramas de Pareto (Figuras 6 e 7), com um nível de 95\% de confiança. 
Figura 6. Diagrama de Pareto dos efeitos das variáveis independentes sobre a acidez total titulável.

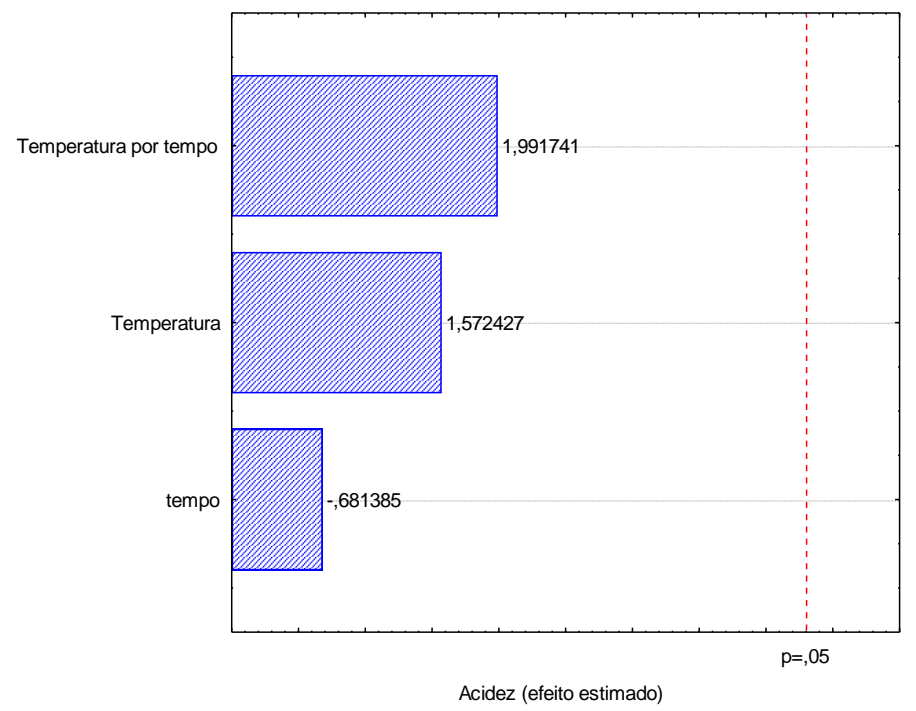

Fonte: Autoria própria.

Figura 7. Diagrama de Pareto dos efeitos das variáveis independentes sobre o ácido ascórbico.

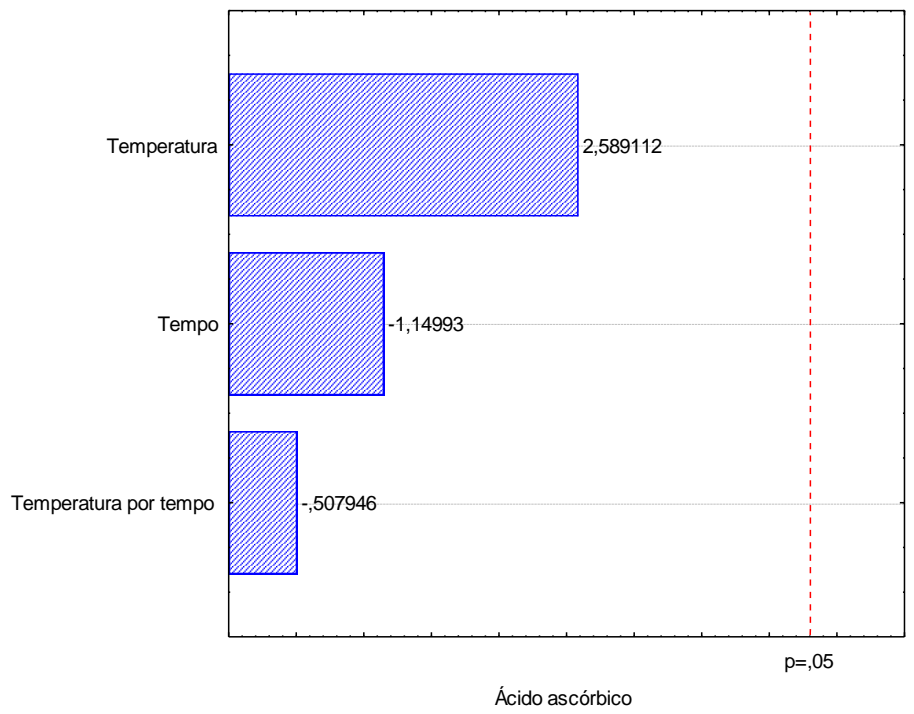

Fonte: Autoria própria.

Ao analisar as Figuras 6 e 7 é possível constatar que o tempo de batimento, temperatura e a interação de ambas não influenciaram significativamente as variáveis respostas dentro da matriz de planejamento estudada e ao intervalo de $95 \%$ de confiança.

Consequentemente, não foi possível gerar superfícies de respostas correspondente ao efeito da temperatura de secagem e tempo de batimento sobre a concentração de ácido ascórbico e acidez total titulável contido na polpa em pó.

\section{Considerações Finais}

Com base nos resultados obtidos, conclui-se que os ensaios realizados a temperatura de $80{ }^{\circ} \mathrm{C}$ apresentaram os melhores desempenhos em relação a viabilidade do tempo de secagem e ao aspecto do pó final. O tempo de batimento não influenciou de 
forma expressiva a cinética de secagem para os ensaios avaliados.

A análise estatística realizada não gerou um modelo estatisticamente significativo para as variáveis em estudo ao nível de $95 \%$ de confiança, diante da matriz elaborada.

De modo geral, pode-se assegurar por meio das análises realizadas que a secagem em camada de espuma da polpa do umbu é adequada, visto que, ao final do procedimento foi obtido um produto com baixo custo de produção e que pode ser armazenado durante um período prolongado, mostrando ser uma alternativa promissora na pós-colheita dessa fruta, uma vez que, promove a retenção de componentes nutricionais e possibilita o consumo do produto na forma de pó.

Como sugestões para trabalhos futuros, propõem-se realizar a secagem em camada de espuma da polpa do umbu com outros emulsificantes, fazer uma análise físico-química detalhada do produto obtido na forma de pó e aplicar modelos matemáticos aos dados experimentais para predizer o fenômeno de secagem.

\section{Referências}

Colocar espaço entre uma referência e outra. Lembre-se que usamos a norma APA.

Alves, F. M. S.; Machado, A. V.; Queiroga, K. H. (2011). Alimentos produzidos a partir de farinhas de caju, obtida por secagem. Revista Verde de Agroecologia e Desenvolvimento Sustentável, 6 (3), 131-138.

Araújo, K. T. A.; Queiroz, A. J. de M..; Figueirêdo, R. M. F. de.; Silva, R. C. da.; Amadeu, L. T. S.; Paiva, Y. F. (2021). Cinética de secagem e determinação do coeficiente de difusão efetivo das polpas de noni e umbu. Research, Society and Development, 10 (4), 1-13.

Brasil. (1978). Resolução - CNNPA nº 12, de 1978. Padrões de Identidade e Qualidade de alimentos e bebidas. Diário Oficial da União.

Brasil. Ministério da saúde. Secretaria de atenção à saúde. Departamento de Atenção Básica. (2014). Guia alimentar para a população brasileira. / ministério da saúde, secretaria de atenção à saúde, departamento de atenção Básica. - (2. ed.), 1. reimpr. - Brasília: ministério da saúde.

Brasil. (2018). Instrução Normativa n ${ }^{\circ} 37$, de $1^{\circ}$ de outubro de 2018. Diário Oficial da União.

Coelho, B. E. S.; Nascimento, M. M. do.; Carvalho, I. R. B. de.; Sousa, K. S. M. de.; Machado, N. S.; Neto, A. F. (2019). Curva de secagem solar e avaliação físico-química da manga "Espada". Journal of Environmental Analysis and Progress, 4 (3), 187-194.

DERAL - Departamento de Economia da Secretaria de Agricultura e Abastecimento do Paraná (SEAB). (2017). Análise da Conjuntura Agropecuária safra 2016/17, Boletim Técnico, Curitiba.

Fellows, P. (2006). Tecnologia do processamento de alimentos: princípios e prática. (2. ed.) Porto Alegre, RS: Artmed, 148 p.

Ferreira, M. N. (2017). Estudo da Secagem de jabuticaba (polpa e casca) pelo método de camada de espuma. Dissertação (Mestrado) - Programa de PósGraduação em Ciência e Tecnologia de Alimentos, Universidade Federal de Goiás.

Gomes, L. D. B. C; Almeida, E. M. de.; Oliveira, E. M. de. (2017). Cinética de secagem em camada de espuma e caracterização física de acerola em pó. Revista Brasileira De Agrotecnologia, 7 (2), 178-184.

Gurgel, C. E. M. R. (2014). Secagem da polpa de graviola (Annona muricata L.) em camada de espuma - Desempenho do processo e características do produto. Dissertação (Mestrado) - Programa de Pós-Graduação em Engenharia Química, Universidade Federal do Rio Grande do Norte.

Instituto Adolfo Lutz. (2008). Métodos químicos e físicos para análise de alimentos. Normas analíticas do Instituto Adolfo Lutz. São Paulo, 1020p. Kudra, T., Ratti, C. (2008). Process and energy optimization in drying of foamed materials. Transactions of the Tambov State Technical University, 14 (4), 812 819.

Moreira, I. S., Silva, W. P., Castro, D. S., Silva, L. M. M., Gomes, J. P., \& Silva, C. M. D. P. S. (2018). Production of kiwi snack slice with different thickness: drying kinetics, sensory and physicochemical analysis. Australian Journal of Crop Science, 12 (5), 778-787.

NEPA - Núcleo de Estudos e Pesquisas em Alimentação. (2011). Tabela Brasileira de Composição de Alimentos (TACO), Campinas: NEPA - UNICAMP, 4. ed. rev., $42 \mathrm{p}$

Neto, J. R. C.; Silva, S. de. M.; Santos, L. F. (2018). Caracterização e qualidade de frutos de limão 'galego’. Colloquium Agrariae, 14 (4), 10 -19.

Pê, P. R., Carneiro, G. G., Pê, F. R.; Castro, D. S., Silva, D. R. S., Marques, L. F. (2016). Secagem de polpa de caqui pelo método de camada de espuma. Holos, 4(32), 77-85.

Pereira, A. S., Shitsuka, D. M., Parreira, F. J., Shitsuka, R. (2018). Metodologia da pesquisa científica. Santa Maria, RS: UFSM, 119 p.

Pinheiro, G. K. I. (2018). Cinética de Secagem dos Frutos de Cajá (Spondias Mombin L.) E Avaliação da Qualidade das Farinhas Produzidas Dissertação (Mestrado) - Programa de Pós-graduação em Tecnologia de Alimentos, Instituto Federal de Educação, Ciência e Tecnologia Goiano. 
Research, Society and Development, v. 10, n. 11, e488101119955, 2021

(CC BY 4.0) | ISSN 2525-3409 | DOI: http://dx.doi.org/10.33448/rsd-v10i11.19955

Rajkumar, P., Kailappan, R. (2006). Optimizing the process parameters for foam mat drying of totapuri mango pulp. The Madras Agricultural Journal, 93, 8698.

Silva, M. I. da; Martins, J. N.; Alves. J. E. de. A.; Costa. F. F. P. da. (2015). Caracterização físico-química da polpa de umbu em camada de espuma. Revista Semiárido de Visu, 3 (2), 82-91.

Silva, R. N. G.; Figueiredo, R.M.F; Queiroz, A.J.M.; Galdino, P.O. (2005). Armazenamento de umbu-cajá em pó. Revista Ciência Rural, 5 (35), $1179-1184$. 